\title{
Human hepatitis e virus among apparently healthy individuals in Ogbomoso, South-Western Nigeria
}

\begin{abstract}
This study was undertaken to determine the seroprevalence, and associated risk factors, of hepatitis E virus. A total of 186 consented apparently healthy individuals were recruited. Interviewer-administered questionnaire was used to obtain the socio-demographic information from the individuals. Blood samples were collected and analyzed for antiHEV using third generation enzyme-linked immunosorbent assay (ELISA). Samples were collected over a period of 10 months (December 2014 - September 2015). Results obtained were analyzed using Statistical Package for Social Sciences (SPSS) version 20.0 statistical software; Chi-square $(\chi 2)$ test was utilized to assess the association between the sociodemographic variables and HEV status while Logistic regression was done to determine the strength of association between the potential risk factors and HEV status (statistical significance was set at $\mathrm{P}<0.05)$. The overall anti-HEV prevalence was $2.7 \%(5 / 186)$. The highest seroprevalence was in the age range 15-25 (4.1\%) years. Males had higher prevalence $(3.2 \%)$. None of the sociodemographic status and potential risk factors were significantly associated with HEV infection $(\mathrm{P}>0.05)$. Preventive public health measures should be maintained among individuals and communities. Data suggest further research with larger population as HEV remains an under-recognized public health challenge.
\end{abstract}

Volume 5 Issue I - 2017

\author{
Oladipo EK,',2 Awoyelu EH,' Oloke JK' \\ 'Department of Pure and Applied Biology (Microbiology/ \\ Virology Unit), Ladoke Akintola University of Technology, \\ Ogbomoso, Oyo State, Nigeria \\ ${ }^{2}$ Department of Microbiology, Adeleke University, Ede, Osun \\ State, Nigeria
}

Correspondence: Oladipo EK, Department of Pure and Applied Biology, Ladoke Akintola University of Technology, Ogbomoso, Oyo State, Nigeria, Tel +2348035369472, Email koladipo2k3@yahoo.com

Received: December 27, 2016 | Published: January 19, 2017

Keywords: Anti-HEV, ELISA, Prevalence, Potential risk factors, Ogbomoso

\section{Background}

Hepatitis E virus (HEV) is a small non-enveloped positive sense single stranded RNA icosahedral virus with a 7.7 kilobase genome that belongs to the genus Herpevirus. ${ }^{1}$ Hepatitis E virus infections occur world-wide. The virus is endemic in regions of the world characterized with poor sanitation (such as Africa, Asia and Central America) as epidemiologic studies have shown the route of transmission to be by faecal-oral route with contaminated food and water being the primary source of infection. ${ }^{2,3}$ However, blood borne transmission of HEV has been investigated as one of the possible risk factors for acquiring hepatitis E virus. ${ }^{1}$ This transmission can be from any apparently healthy individual who can be potential blood donor to healthy/unhealthy individuals during blood transfusion. Other possible risk factors are not limited to previous history of surgery or alcohol intake. ${ }^{4}$ Even though hepatitis E infections are self-limiting among immunocompetent individuals, persistency can result into fulminant hepatitis. ${ }^{3,5}$

Since the discovery of HEV, several outbreaks of the infection have been reported among pregnant women, ${ }^{6}$ HIV positive individuals, ${ }^{1}$ sick individuals, ${ }^{3}$ animal handlers ${ }^{7}$ as well as apparently healthy individuals. ${ }^{8}$ Thus, apparently healthy individuals are considered a high risk group for HEV infection in endemic areas; however, this assumption is based on outbreak reports only, as no studies have been performed comparing exposure to HEV among this group.

World-wide, HEV infections are recognized serious threat to public health particularly in developing countries, where the virus is endemic. ${ }^{9}$ In Nigeria, seroprevalences differ considerably, ranging from 5.5\% in Ogbomoso, ${ }^{1} 13.4 \%$ in Ekiti, ${ }^{3} 17.8 \%$ in Lagos ${ }^{7}$ to $42.7 \%$ in Plateau, ${ }^{6}$ but little is known on potential risk factors involved in acquiring the virus. Thus, the present study aimed at investigating the seroprevalence of antibodies against HEV and studying potential risk factors, other than through faecal-oral transmission, associated with blood borne transmission in different areas of Ogbomoso.

\section{Materials and methods}

\section{Study area}

The study was carried out at Ogbomoso, Oyo State in the tropical belt of Southern Western part of Nigeria (Africa). Its coordinates are $8^{\circ} 7^{\prime} 60^{\prime \prime} \mathrm{N}$ and $4^{\circ} 16^{\prime} 0^{\prime \prime} \mathrm{E}$ in DMS (Degrees Minutes Seconds) or 8.13333 and 4.26667 (in decimal degrees).

\section{Study population}

Consenting apparently healthy individuals residing in different areas of Ogbomoso in the age range 16 to 65 years were enrolled for this study between December 2014 and September 2015. Structured questionnaires about socio-demographic characteristics and other relevant information were administered to all participating subjects as well as verbal and informed consent form prior blood sample collection. The study protocol was in accordance with the amended Declaration of Helsinki. Any individual who refused to give consent as well as provide necessary information on the questionnaire was excluded from the study.

\section{Blood sample collection}

Five $\mathrm{ml}$ of venous blood samples was collected in tubes with no anticoagulant. Blood sample was spun with a bench centrifuge at $3000 \mathrm{rpm}$ for 10 minutes to obtain serum. Serum was obtained and stored at $-20{ }^{\circ} \mathrm{C}$ until ready for analysis.

\section{Antibody detection}

Commercially available third generation ELISA kits (WKEA MED SURPLUS CORP, China) were employed to determine specific antibodies against hepatitis $\mathrm{E}$ virus (HEV) according to the manufacturer's instructions. The optical density was read using the Emax endpoint ELISA microplate reader (Molecular Devices, California, and USA) and the result was interpreted according to the manufacturer's instruction. 


\section{Statistical Analysis}

The prevalence of antibodies to HEV was determined from the proportion of the positive individuals in the total population studied and expressed as percentages. The data obtained was analyzed using a Statistical Package for Social Sciences (SPSS version 20). They were organized and summarized in terms of frequencies and the results of the study were presented in tables and figures. Chi-square $(\chi 2)$ test was utilized to assess the association between the socio-demographic variables and HEV status. Statistical significance was set at $\mathrm{P}<0.05$. Pie and bar charts were used for presenting the analyzed data. Logistic regression was done to determine the strength of association between the potential risk factors and HEV status.

\section{Results}

\section{Demographic characteristics of the study population}

The study included 186 participants, consisting of 93 males and 93 females respectively, in the age range 16-65 years with a mean age of $31.62 \pm 7.85$ years. The sociodemographic characteristics of the participants is shown in Table 1. The highest participants were in the age range $26-35$ years $(51.1 \%)$ while the lowest was in the age range $56-65$ years $(0.5 \%)$.

Out of the 186 study participants, 5 (2.7\%) sera were positive for anti-HEV as shown in Table 2.

Table I Socio-demographic factors of the study participants

\begin{tabular}{llll}
\hline Parameter & Level & Frequency & Percentage \\
\hline \multirow{4}{*}{ Age } & $15-25$ & 49 & 26.3 \\
& $26-35$ & 95 & 51.1 \\
Sex & $36-45$ & 32 & 17.2 \\
& $46-55$ & 9 & 4.3 \\
Marital Status & $56-65$ & 1 & 0.5 \\
& Male & 93 & 50 \\
& Female & 93 & 50 \\
& Monogamy & 132 & 71.0 \\
& Polygamy & 9 & 4.8 \\
& Single & 45 & 24.2 \\
Occupation & Artisan & 34 & 18.3 \\
& Civil servant & 54 & 29.0 \\
& Student & 42 & 22.6 \\
& Trader & 47 & 25.3 \\
& Others & 1 & 0.5 \\
& None & 8 & 4.3 \\
& Primary & 17 & 9.1 \\
Education & Secondary & 44 & 23.7 \\
& Tertiary & 106 & 57.0 \\
& Others & 17 & 9.1 \\
& None & 2 & 1.1 \\
\hline
\end{tabular}

Table 2 Seroprevalence of HEV infections among the study participants

\begin{tabular}{ll}
\hline Status & Total (\%) \\
\hline Reactive & $5(2.69)$ \\
Non-Reactive & $181(97.3 \mathrm{I})$ \\
Total & $186(100.00)$ \\
\hline
\end{tabular}

Prevalence of anti-HEV status in relation to sociodemographic characteristics

The distribution of seropositive samples according to gender, occupation, education and marital status of the study participants are shown in Table 3. Seroprevalence in male and female was 3.2\% $(3 / 93)$ and $2.2 \%(2 / 93)$ respectively. However, there was no statistical significant difference $(\mathrm{p}>0.05)$ in anti-HEV positivity and sex distribution.
Table 3 Seroprevalence of HEV infection in relation to sociodemographic characteristics

\begin{tabular}{|c|c|c|c|c|c|c|}
\hline \multicolumn{7}{|l|}{ HEV Status } \\
\hline Parameter & Level & $\begin{array}{l}\text { Positive } \\
\text { (\%) }\end{array}$ & $\begin{array}{l}\text { Negative } \\
\text { (\%) }\end{array}$ & Df & $\begin{array}{l}\text { Chi- } \\
\text { square }\end{array}$ & $e^{P \text {-value }}$ \\
\hline \multirow{5}{*}{ Age } & $15-25$ & 2 (4.I\%) & 47 (95.9\%) & & & \\
\hline & $26-35$ & $3(3.2 \%)$ & 92 (96.8\%) & & & \\
\hline & $36-45$ & $0(0.0 \%)$ & $32(100.0 \%)$ & 4 & 1.604 & 0.808 \\
\hline & $46-55$ & $0(0.0 \%)$ & $9(100.0 \%)$ & & & \\
\hline & $56-65$ & $0(0.0 \%)$ & I ( $100.0 \%)$ & & & \\
\hline \multirow{3}{*}{ Sex } & Male & $3(3.2 \%)$ & 90 (96.8\%) & & 0206 & $0<50$ \\
\hline & Female & $2(2.2 \%)$ & 91 (97.9\%) & 1 & 0.206 & 0.650 \\
\hline & Monogamy & $3(2.3 \%)$ & 129 (97.7\%) & & & \\
\hline \multirow[t]{4}{*}{ Marital status } & Polygamy & $0(0.0 \%)$ & $9(100.0 \%)$ & 2 & 0.886 & 0.648 \\
\hline & Single & $2(4.4 \%)$ & 43 (95.6\%) & & & \\
\hline & Artisan & I (2.9\%) & $33(97.1 \%)$ & & & \\
\hline & Civil servant & $0(0.0 \%)$ & $54(100.0 \%)$ & & & \\
\hline \multirow{6}{*}{ Occupation } & Student & $2(4.8 \%)$ & 40 (95.2\%) & & 2000 & 1 \\
\hline & Traders & $2(4.3 \%)$ & $45(4.3 \%)$ & 5 & 2.880 & 0.118 \\
\hline & Others & $0(0.0 \%)$ & I (I00.0\%) & & & \\
\hline & None & $0(0.0 \%)$ & $8(100.0 \%)$ & & & \\
\hline & Primary & I (5.9\%) & $16(94.1 \%)$ & & & \\
\hline & Secondary & $0(0.0 \%)$ & $44(100.0 \%)$ & & & \\
\hline \multirow[t]{3}{*}{ Education } & Tertiary & $3(2.8 \%)$ & 103 (97.2\%) & 4 & 1.873 & 0.759 \\
\hline & Others & I (5.9\%) & $16(94.1 \%)$ & & & \\
\hline & None & $0(0.0 \%)$ & $2(100.0 \%)$ & & & \\
\hline
\end{tabular}

Age-specific prevalence of anti-HEV decreased with age, with $4.1 \%(2 / 49)$ among the subjects in the age range $16-25$ years, $3.2 \%$ $(3 / 95)$ in the age group 26-35 years and $0.0 \%(0 / 42)$ over 35 years. There was no significant difference $(p>0.05)$ between seropositivity and age distribution.

Occupation wise, $4.8 \%(2 / 42)$ was recorded among students, $4.3 \%$ (2/47) among traders, $2.9 \%(1 / 34)$ among artisans. There was no record of prevalence among those who had other occupation or those that had no occupation. Also, there was no statistical significant difference $(\mathrm{p}>0.05)$ between seropositivity and occupation.

Considering educational status, the highest prevalence 5.9\% (1/17) was recorded among those that had primary and other education respectively followed by $2.8 \%(3 / 106)$ among those that had tertiary education. There was no statistical significance between seropositivity and education.

Considering marital status, participants who were single had a higher prevalence of $4.4 \%(2 / 45)$ than $2.3 \%(3 / 132)$ prevalence in the monogamy group. However, there was no statistical significant effect of marital status on HEV seroprevalence.

\section{Association between potential risk factors and HEV status}

Associations between potential risk factor and HEV status is presented in Table 4. From the analysis, there was no statistical association $(\mathrm{P}>0.05)$ between $\mathrm{HEV}$ and the potential risk factor considered. The result showed that there was a prevalence of $2.7 \%$ among the study participants with no record of previous history of blood transfusion as compared with those that with previous history of blood transfusion. However, there was no statistical significance $(\chi 2=0.201, \mathrm{df}=1, \mathrm{P}=0.654)$. There is a 1 -fold risk of getting infected among those who had previous history of blood transfusion $(95 \% \mathrm{CI}$ $=0.934-0.990, \mathrm{OR}=1.0$ ). 
Table 4 Association of potential risk factor and HEV

\begin{tabular}{|c|c|c|c|c|c|}
\hline \multirow{2}{*}{ Variables } & \multicolumn{2}{|l|}{ Status } & \multirow{2}{*}{ OR } & \multirow{2}{*}{$95 \% \mathrm{Cl}$} & \multirow{2}{*}{$P$-value } \\
\hline & Positive N (\%) & Negative $\mathbf{N}(\%)$ & & & \\
\hline \multicolumn{6}{|l|}{$\begin{array}{l}\text { History } \\
\text { of Blood } \\
\text { Transfusion }\end{array}$} \\
\hline No & $5(4.5)$ & I74(95.5) & 0.961 & $0.934-0.990$ & 0.654 \\
\hline Yes & $0(0.0)$ & $7(100.0)$ & I & & \\
\hline
\end{tabular}

\section{Discussion}

The overall seroprevalence of anti-HEV recorded was $2.7 \%$. The prevalence is the same with the prevalence recorded in United States. ${ }^{10}$ However, it is lower than a prevalence of $22.5 \%$ in Rural Bangladesh, ${ }^{8}$ $14.3 \%$ in Austria, ${ }^{2} 5.38 \%$ in Italy, ${ }^{4} 5.8 \%$ in Ghana ${ }^{11} 18.8 \%$ among schistosomiasis patients in Northeastern Brazil. ${ }^{12}$ It is higher than a $2.6 \%$ prevalence recorded at Switzerland. ${ }^{13}$

In Iran, the prevalence recorded in this study falls within the prevalence of $1.1 \%-14.2 \%$ and $1.6 \%-11.3 \%$ recorded among the general population and patients infected with other hepatitis viruses respectively, but it is lower than $4.5 \%-14.3 \%, 6.1 \%-22.8 \%$, $6.3 \%-28.3 \%, 27.5 \%, 30.8 \%$ and $10 \%-16.4 \%$ recorded among blood donors, injecting drug users, hemodialysis patients, patients with chronic liver disease, kidney transplant recipient patients and human immunodeficiency virus-infected patients respectively. ${ }^{14}$ This difference may be ascribed to difference in geographical location,

From previous studies in Nigeria, the prevalence observed in this study is lower than a $5.5 \%$ prevalence recorded in Ogbomoso among individuals infected with HIV, $8.3 \%$ prevalence observed in Ekiti, ${ }^{3} 31.1 \%$ in Plateau, ${ }^{6} 7.7 \%$ in Cross river. ${ }^{15}$ The difference in the prevalence may be ascribed to differences in the sensitivity and specificity of the assay used in various studies, difference in study groups, socio-economic, cultural, hygienic and climatic conditions.

The individuals' ages varied from 15 to 65 years. This study showed a decreasing seroprevalence, from $4.1 \%$ in the age range $15-25$ years to $3.2 \%$ in the age range $26-35$ years. This age-specific prevalence might be due to increased exposure to high-risk environments through consumption of contaminated food and water among the age group 15-25 years as compared to the age group 26-35 years. This is in agreement with the reports of Ekanem et al. ${ }^{15}$ and Martinson et al. ${ }^{16}$ that recorded a high prevalence among the age group 16-18 years that fall within the recorded age group. However, there was no significant association of age to anti-HEV positivity.

In the present study, there was no significant association between sex and anti-HEV positivity. Males, however, had a higher prevalence rate of $3.2 \%$ as compared with the females who had a prevalence rate of $2.2 \%$. The finding might be attributed to increased exposure of males to contaminated water, contaminated food sources and respective sanitary conditions as compared to females. ${ }^{2}$ This disagrees with the reports of Junaid et al., ${ }^{6}$ Ekanem et al. ${ }^{15}$ and Ofosu-Appiah et al. ${ }^{11}$ where higher prevalence was recorded among females as compared with males.

Considering marital status, a higher prevalence (4.4\%) was recorded among the singles as compared to the married $(2.3 \%)$. This disagrees with the reports of Labrique et al. ${ }^{8}$ and Junaid et al. ${ }^{6}$ where a higher prevalence was documented among married people than singles. This might be attributed to increased sexual activity among singles as compared to married in the study area, which can lead to sexual transmission. There was no statistical significant association between marital status and anti-HEV positivity.
Considering occupation, there was a record of higher prevalence among the students $(4.8 \%)$ as compared to traders $(4.3 \%)$ and artisans $(2.9 \%)$ respectively. This might be attributed to low personal hygiene and overcrowding where students reside. This suggests that person-toperson contact is probably a major transmission factor among students. Overcrowded areas carry the risk of poor sanitation conditions and low standard of lifestyle.

From the study, previous history of blood transfusion was not statistically significant to acquisition of HEV. This disagrees with the report of Junaid et al. ${ }^{6}$ who recorded a strong association of HEV IgM with history of blood transfusion, but not with IgG. Although, there is no strong evidence that HEV is being transmitted through blood transfusion or blood products. ${ }^{17}$

Considering educational background, individuals who had primary education and other form of education had higher prevalence rate $(5.9 \%)$ as compared to those that had tertiary education $(2.8 \%)$. This is consistent with the findings of Junaid et al. ${ }^{6}$ that low educational attainment is related to low socioeconomic status which in turn results in lack of knowledge about the possible risk factors associated with HEV infection.

In conclusion, this study suggests that a significant number of people in the study area had been exposed to HEV. Findings from the study suggests that socioeconomic status and education are the biggest factor behind higher prevalence rates of HEV. Preventive public health measures should be maintained among individuals and communities. Proper blood screening should be imbibed and maintained by blood banks.

\section{Acknowledgements}

We are thankful to all the study participants and staff in the microbiology research laboratory of Prof. J.K. Oloke at Ladoke Akintola University of Technology, Ogbomoso, Oyo State, Nigeria who contributed immensely to the study.

\section{Conflicts of interest}

None.

\section{References}

1. Oladipo EK, Oloke JK, Awoyelu EH, et al. Detection of Hepatitis E Virus among HIV Infected Individuals in Ogbomoso, South-western Nigeria. British Journal of Virology. 2015;2(4):62-67.

2. Lagler H, Poeppl W, Winkler H, et al. Hepatitis E virus seroprevalence in Austrian adults: a nationwide cross-sectional study among civilians and military professionals. PLoS One. 2014;9(2):e87669.

3. Adesina OA, Japhet MO, Donbraye E, et al. Anti-hepatitis E virus antibodies in sick and healthy individuals in Ekiti State, Nigeria. African Journal of Microbiology Research. 20093(9):533-536.

4. Lanini S, Garbuglia AR, Lapa D, et al. Epidemiology of HEV in the Mediterranean basin: 10-year prevalence in Italy. BMJ Open. 2015;5(7):e007110.

5. Jose-Manuel E. Light and darkness: prevalence of hepatitis E virus infection among the general population. Scientifica (Cairo). 2014:481016

6. Junaid SA, Agina SE, Abubakar KA. Epidemiology and associated risk factors of hepatitis E virus infection in Plateau State, Nigeria. Virology (Auckl). 2014;5:15-26.

7. Meseko C, Odurinde O, Odaibo G, et al. Serological evidence and risk factors associated with hepatitis E virus infection in pigs and human at an intensive piggery complex, Lagos Nigeria. Journal of Healthcare Communication 1: 1.2016. 
8. Labrique AB, Zaman K, Hossain Z, et al. Epidemiology and risk factors of incident hepatitis $\mathrm{E}$ virus infections in rural Bagladesh. Am J Epidemiol. 2010;172(8):952-961.

9. Shata MT, Navaneethan U. The mystery of hepatitis E seroprevalence in developed countries: is there subclinical infection due to hepatitis $\mathrm{E}$ virus? Clin Infect Dis. 2008;47(8):1032-1034.

10. Mahajan R, Collier MG, Kamili S, et al. Hepatitis E virus among persons who inject drugs, San Diego, California, USA, 2009-2010. Emerg Infect Dis. 2013;19(10):1664-1666.

11. Ofosu-Appiah LH, Joseph HKB, Theophilus A, et al. Serological and molecular evidence of hepatitis $\mathrm{E}$ infection among patients with suspected viral hepatitis seen at Korle-Bu teaching hospital, Accra. Journal of Scientific Research \& Reports. 2016;10(1):1-10.

12. Passos-Castilho AM, de Sena A, Domingues AL, et al. Hepatitis E virus seroprevalence among schistosomiasis patients in Northeastern Brazil. Braz J Infect Dis. 2016;20(3):262-266.
13. Kovari H, Ledergerber B, Battegay M, et al. Incidence and risk factors for chronic elevation of alanine aminotransferase levels in HIV-infected persons without hepatitis B or C virus co-infection. Clin Infect Dis. 2010;50(4):502-511

14. Tadesse E, Metwally L, Abd-El Hamid AES. High prevalence of antihepatitis E virus among Egyptian blood donors. Journal of General and Molecular Virology. 2013;5(1):9-13.

15. Ekanem E, Ikobah J, Okpara H, et al. Seroprevalence and predictors of hepatitis E infection in Nigerian children. J Infect Dev Ctries. 2015;9(11):1220-1225.

16. Martinson FE, Marfo VY, Degraaf J. Hepatitis E virus seroprevalence in children living in rural Ghana. West Afr J Med. 1999;18(2):76-79.

17. Arankalle VA, Chobe LP. Retrospective analysis of blood transfusion recipients: evidence for post-transfusion hepatitis E. Vox Sang. 2000;79(2):72-74 